\title{
Producción CIENTífica de los decanos de LAS FACULTADES DE MEDICINA DE BOLIVIA
}

\author{
SCIENTIFIC PRODUCTION BY MEDICAL SCHOOL DEENS IN BOLIVIA
}

'Estudiante de Medicina. Universidad Nacional de Asunción

${ }^{2}$ Estudiante de medicina de nivel pregrado Universidad privada Franz Tamayo

Correspondencia a:

Sebastián Joaquín Ocampo Rojas.

Correo:sebas13ocampo@ gmail.com

Telefono: +595981705100

ORCID: https://orcid.org/0000

0003-4183-4960

https://orcid.org/0000-00022389-1630

palabras clave: Investigación, Política de Investigación en Salud, Evaluación de la Investigación en Salud, Promoción de la Investigación, Informe de Investigación.

Key words: Research, Health Research Policy, Health Research Evaluation, Research Promotion, Research Report.

Procedencia y arbitraje: comisionado, no sometido a arbitraje.

Recibido para publicación: 15 de junio 2020

Aceptado para publicación: 20 de junio 2020

Citar como:

Ocampo Rojas SJ. Producción científica de los decanos de las facultades de medicina de bolivia. Rev Cient Cienc Med 2020; 23(2): 278-279

Sebastián Joaquín Ocampo Rojas ${ }^{1}$ Reina Ruth Saucedo Saldaña ${ }^{2}$

Sr. Editor:

Nas su revista nuestra perspectiva sobre la publicación científica de los decanos de las facultades de medicina de las universidades bolivianas. Como usted sabe, actualmente la investigación científica a nivel de pregrado es uno de los indicadores del Sistema de Acreditación Regional de Carreras Universitarias de los Estados parte del Mercosur (ARCU-SUR) ${ }^{1}$. Un aspecto muchas veces olvidado en nuestro continente, pero que afortunadamente se está teniendo en cuenta en nuestra formación académica.

Por consiguiente, hemos realizado una búsqueda en la guía de universidades del Estado Plurinacional de Bolivia, donde se agrupan en universidades públicas autónomas, universidades privadas adscritas al Comité Ejecutivo de la Universidad Boliviana (CEUB), universidades privadas, universidades indígenas $y$ universidades de régimen especial. La Comisión Nacional de Acreditación de Carreras Universitarias (CNACU) reconoce 25 universidades que disponen de la carrera de medicina en sus diferentes sedes, dando una totalidad de 37 facultades de medicina ${ }^{2}$. Actualmente 8 de estas universidades se encuentran acreditadas en el ARCU-SUR, 5 universidades públicas autónomas, 1 universidad privada adscrita al CEUB y 2 universidades privadas ${ }^{1}$.

A través del motor de búsqueda Google se identificó cada facultad de medicina con su actual decano o jefe de carrera, posteriormente se realizó la búsqueda por nombre y apellido, con sus distintas variaciones en los buscadores Scielo Bolivia, Scielo, Pubmed y Scopus. Se clasificó según el tipo publicación en artículo original, artículo de revisión, reporte de caso, carta al editor $y$ otras. Se los nombrará "decano \#" en orden decreciente según a la cantidad de publicaciones.

Se encontró que solamente 3 decanos han publicado alguna vez un trabajo científico en una revista indexada a los buscadores de Scielo, sin embargo, no se encontró ninguna publicación en Pubmed $y$ solo 1 en Scopus. De estos aportes, los decanos 1 y 3 produjeron al menos un artículo original, 5 y 1 respectivamente. Hubo 2 artículos de revisión publicados por el decano 1. El decano 2 realizó dos editoriales y un reporte de caso, en tanto que el decano 1 publicó 2 reportes de caso.

Como puede verse la publicación científica por parte de los jefes de las casas de estudio es baja, similar a los encontrados por RiosGonzález y Ortiz-Martínez et al. en Paraguay y Argentina, respectivamente ${ }^{3,4}$. Podría reflejarse la falta de un ejemplo y motivación por parte de los decanos de la facultad, en que los estudiantes de medicina de Bolivia tengan una baja producción científica en Bolivia, como lo expresa Carvajaly la poca participación estudiantip, ${ }^{5}$.

En Bolivia la investigación en pregrado es desvalorada junto a las sociedades científicas de las universidades por sus autoridades principales de la carrera de medicina ya que muchas veces las misma autoridades desconocen el proceso porelcualse pasa para elaborar una investigación y también muchos de las mismas autoridades no ven la importancia de publicar, ocasionando que más profesional de salud ignoren la relevancia de la investigación dentro de un país y tengamos a larga una déficit en el área tanto.

Con este trabajo se pretende hacer un hincapié a la alta necesidad que se tiene de fomentar $y$ alimentar la cultura de investigar $y$ aprender a publicar ya que de ello también depende mucho la mejora del sistema en salud. 


\section{REFERENCIAS}

1.ARCU-SUL. Bolivia [Internet]. [citado el 4 de mayo de 2020]. Disponible en: http://edu.mercosur.int/arcusur/index.php/ es/bolivia

2. Ministerio de Educación, Gobierno del Estado Plurinacional de Bolivia. Gula de Universidades del Estado Plurinacional de Bolivia 2016 [Internet]. [citado el 4 de mayo de 2020]. Disponible en: https:/ www minedu.go6.6o/index. php? option $=\mathrm{com}$

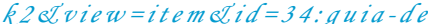
universidades-del-estado-plurinacional-de Golivia-2016a'Ttemid $=887$

3.Rios-González

Scientific production by medical school faculties in Paraguay. Educacion Me dica[Internet].2018;19(S2):220-1. Disponible en: https://www.elsevier.es/ en-revista-educacion-medica-71-articuloproduccion-cientifica-decanos-facultades medicina-S1575181318300172

4.Ortiz-Martínez Y, Echavarría-Cadena CA. Producción cientifica de los decanos de facultades de medicina de Argentina[Internet]. Gaceta Sanitaria. 2017; 31(2): 167. Disponible en: http: scielo.isciuies/scielo.php? script=sci_arttext Qtpid $=$ S0213-91112017000200167

5.Taype-Rondán Á, Palma-Gutiérrez
E, Palacios-Quintana M, CarbajalCastro C, Ponce-Torres C. Producción cientffica estudiantilen Latinoamérica: un análisis de las revistas médicas de habla hispana indizadas en SciELO, 2011. FEM Rev la Fund Educ Médica. 2014;17(3):171-7. Disponible en: http://scielo. isciü.es/scielo. php? script $=$ sci arttextatpid $=$ S2014-98322014000300007 6.Carvajal Tapia, A. UNA VISION PANORAMICA DELA PRODUCTIVIDAD CIENTIFICA EN SALUD DE BOLIMA [Internet]. Rev. Méd. La Paz. 